\title{
Isolation \& identification of Shigella species from food and water samples of Quetta, Pakistan
}

Saima ${ }^{1}$, Abdul Samad ${ }^{1}$, Ferhat Abbas ${ }^{1}$, Roomeela $^{1}$, Mohammad Rizwan $^{2 *}$, Mohammad Yousaf ${ }^{1}$, Yousaf Hassan ${ }^{1}$, Muhammad Naeem ${ }^{3}$, Mohammad Zahid ${ }^{4}$, Olena Pokryshko ${ }^{5}$, Silvia Diaconescu ${ }^{6}$ and Sundus Saifullah ${ }^{1}$

1. Center for Advanced Studies in Vaccinology and Biotechnology (CASVAB), University of Balochistan-Pakistan

2. Bio Technology \& Molecular Biology, CASVAB, University of Balochistan-Pakistan

3. Department of Microbiology, University of Balochistan-Pakistan

4. Provincial TB Control Program, Provincial Reference Laboratory, Fatima Jinnah General \& Chest Hospital, Quetta, Balochistan-Pakistan

5. Department of Microbiology, Virology and Immunology, Ternopil State Medical University-Ukraine

6. Accounting Services, Targu Jiu, Gorj-Romania

*Corresponding author's email: khanr6847@gmail.com

Citation

Saima, Abdul Samad, Roomeela, Mohammad Rizwan, Ferhat Abbas, Mohammad Yousaf, Yousaf Hassan, Muhammad Naeem, Mohammad Zahid, Olena Pokryshko, Silvia Diaconescu and Sundus Saifullah. Isolation \& identification of Shigella species from food and water samples of Quetta, Pakistan. Pure and Applied Biology. Vol. 7, Issue 1, pp227-235. http://dx.doi.org/10.19045/bspab.2018.70027

Received: 25/11/2017 Revised: 06/02/2018

Accepted: 09/02/2018

Online First: 14/02/2018

\section{Abstract}

Shigella species are frequently associated with food and water borne infections leading to acute invasive enteric infections. Annually there are 165 million cases of shigellosis, of which 163 million are in developing countries and the incidence is highest among children. The study was aimed to isolate and identify Shigella species from food and water samples. The isolates were identified by using conventional biochemical tests. Total of 100 samples (50 ready-to-eat salad +50 household water) were randomly collected aseptically. Out of 100 samples analyzed, 27 (27\%) were found positive for Shigella species. Out of these 27 positive samples, $16(32 \%)$ were from ready-to-eat salad samples and $11(22 \%)$ were from water. Incidence of Shigella species in Quetta city water (28\%) is higher as compared to water collected from outside the city which is (16\%). Shigella flexneri was the most frequent isolate (70\%) observed in this study. The high level of Shigella species prevalence was observed during the month of April-June. This study revealed that the use of raw animal manure as fertilizer, irrigation of vegetables with fecal contaminated water, a poor sanitary system and improper treatment of water supplies can increase potential risks to the consumer. Adaptation and application of Hazard Analysis and Critical Control Point (HACCP) can decrease the possibility of contamination and eliminate pathogenic microorganisms. Awareness regarding communicable diseases also helps control shigellosis and other diarrheal disease.

Keywords: Biochemical tests; Quetta; Salad; Shigella; Water

Introduction

Shigellosis or Bacillary dysentery, a gastrointestinal disease caused by Shigella species, is recognized as a serious health problem throughout the world. It is mostly found in developing countries due to improper 
waste management, poor hygienic condition and unsafe drinking water. In industrialized nations, it is mostly due to travel to unindustrialized countries and consumption of contaminated food material [1]. Globally, mortality and morbidity due to shigellosis were found to be highest in children under five years old $[2,3]$.

Worldwide, Shigella is responsible for 80-165 million cases of disease and 600,000 deaths annually, of which 1.5 million in developed countries and 163 million are reported in developing countries [4]. In the United state, about 500,000 cases of shigellosis are reported each year $[5,6]$. In Africa, it is estimated that more than 8 million Shigella infections occur per year, whereas in Asia 91 million cases and 414,000 deaths occur annually [7].

The first report on the Shigella isolation and characterization was published by Kiyoshi Shiga in 1897 [8]. The genus Shigella is classified in the family Enterobacteriaceae. It is gram negative bacilli, non-spore forming, non-motile, $0.5-0.7 \mu \mathrm{m}$ in size and facultative anaerobic pathogen that are closely related to Escherichia coli. It is differentiated from Escherichia coli on the basis of serology, pathogenesis and physiology. Shigella species usually ferment sugars without production of gas and lactose, urease and oxidase negative [9].

The Shigella genus is divided into four species that are Shigella dysenteriae (serogroup A), Shigella flexneri (serogroup B), Shigella boydii (serogroup C) and Shigella sonnei (serogroup D). According to biochemical characterization and serological properties, these species are further distributed into several serotypes, as Shigella dysenteriae have 15 serotypes, Shigella flexneri have 14 serotypes and subserotypes, Shigella boydii have 20 serotypes and Shigella sonnei with a single serotype $[10,11]$. These species are the etiological agent of Shigellosis also known as bacillary dysentery. The symptoms can range from mild watery diarrhea to severe inflammatory dysentery with the passage of mucoid and bloody stools. The other clinical manifestation includes abdominal cramping, fever, nausea, malaise, vomiting and convulsions. Other complications of shigellosis include septicemia, dehydration, joint pains, hypoglycemia, hemolytic uremia and neurological complications [12, 13].

Mode of transmission is via fecal-oral route and by direct contact with an infected individual. The Shigella species are highly infectious, as only 10-100 organisms are enough to cause disease and the bacteria is more resistant to stomach acid and can easily pass through the gastric acid barrier [14].

A combination of antibiotics and oral rehydration can lead to the rapid resolution of disease. Currently, there is no protective vaccine targeting Shigella, but several vaccine candidates for Shigella are under development including killed, live attenuated, ribosomal and conjugate vaccine [15].

\section{Materials and methods Sample Collection}

A total of 100 samples (50 ready-to-eat salad +50 household water) were randomly collected from different areas of Quetta, during January 2017 to June 2017. Ready-toeat salad samples were collected in a sterilized stomacher bag from different shops and water samples were collected in the sterilized Duran bottles from Quetta city and outside the city. After collection, the samples were kept in thermopol box filled with crushed ice and transported to Bacteriology Laboratory, Center for Advanced Studies in Vaccinology and Bacteriology (CASVAB), University of Balochistan for further processing. All samples were processed within 4-5 hour of collection.

\section{Isolation of Shigella}

Ready-to-eat salad and water samples were processed according to the International Organization for Standardization (ISO) 21567: 2004 [16] with some modification. For isolation of Shigella species $25 \mathrm{~g}$ of each salad 
sample was aseptically removed using sterile scalpel and was transferred into a stomacher bag, and $25 \mathrm{ml}$ of each water sample was also transferred into a stomacher bag for processing. The samples were inoculated with $225 \mathrm{ml}$ of Shigella Broth (Oxoid, UK) supplemented with novobiocin $(0.5 \mu \mathrm{g} / \mathrm{ml})$, following homogenization of 1 minute in a stomacher bag and was incubated at $41.5^{\circ} \mathrm{C}$ for 18- 24 hour in an anaerobic environment. After incubation, each sample was streaked onto selective and differential agar plates (Hektoen Enteric Agar (HEA) (oxoid, UK), Xylose Lactose Deoxycholate (XLD) Agar (Oxoid, UK) and MacConkey Agar (MAC) (Oxoid, UK)) and plates were incubated at $37^{\circ} \mathrm{C}$ for $18-24$ hour. Suspected colonies of Shigella from each selective medium were picked, and were streaked onto nutrient agar plates and incubated at $37^{\circ} \mathrm{C}$ for $18-24$ hour.

\section{Identification of Shigella}

Typical colonies were selected from Nutrient Agar plates and were subjected to slide preparation, Gram staining, microscopic observation and biochemical tests. Pure colonies were identified by biochemical tests, triple sugar iron agar (TSI), Motility test, Urease test, Indole test, L-lysine decarboxylase, L-ornithine decarboxylase, Sodium acetate test, Christensen's citrate test and sugar fermentation test (dulcitol, glucose, lactose, mannitol, raffinose, salicin, sorbitol, sucrose and xylose) (all from Oxoid, UK).

\section{Results}

In this study, a total of 100 samples were examined out of which $27(27 \%)$ were found Shigella positive. Out of these 27 positive samples, 16 (32\%) were from ready-to-eat salad samples and 11 (22\%) were from water as shown in (Figure 1). The percentage of
Shigella species in water samples collected from the Quetta city (28\%) was higher as compared to those collected from outside the city (16\%) as shown in (Figure 2). The isolated Shigella species were found Gram negative bacilli, facultative anaerobic, non-motile and non-sporulating.

The predominant species of Shigella identified by biochemical tests, were Shigella flexneri and Shigella dysenteriae. Among the biochemical tests, negative results were noticed in Urease, Lysine decaboxylase, Ornithine decarboxylase, inability of Sodium acetate and Christensen's citrate utilization. In Triple sugar iron test, isolates produced an alkaline slant and an acid butt with no hydrogen sulphide and gas production for both Shigella flexneri and Shigella dysenteriae. Both species produced the formation of red ring which indicated the positive reaction (production of indole). Variable results were obtained in tests of mannitol, raffinose and xylose, while fermentation was seen in glucose, dulcitol and sorbitol. Changing of sugar color showed the positive results and there was no fermentation in sucrose, salicin and lactose test. The biochemical tests of Shigella flexneri and Shigella dysenteriae isolates are shown in the (Table 1). The percentage of Shigella flexneri was (26\%) and $(12 \%)$ in ready-to-eat vegetables and water, respectively. In contrast, the percentage of Shigella dysenteriae was (6\%) and (10\%) in ready-to-eat vegetables and water, respectively as shown in (Figure 3).

The month wise prevalence rate of Shigella was minimum (12\%) in samples collected during January to March, while maximum (39\%) in samples collected during April to June as shown in (Figure 4). 


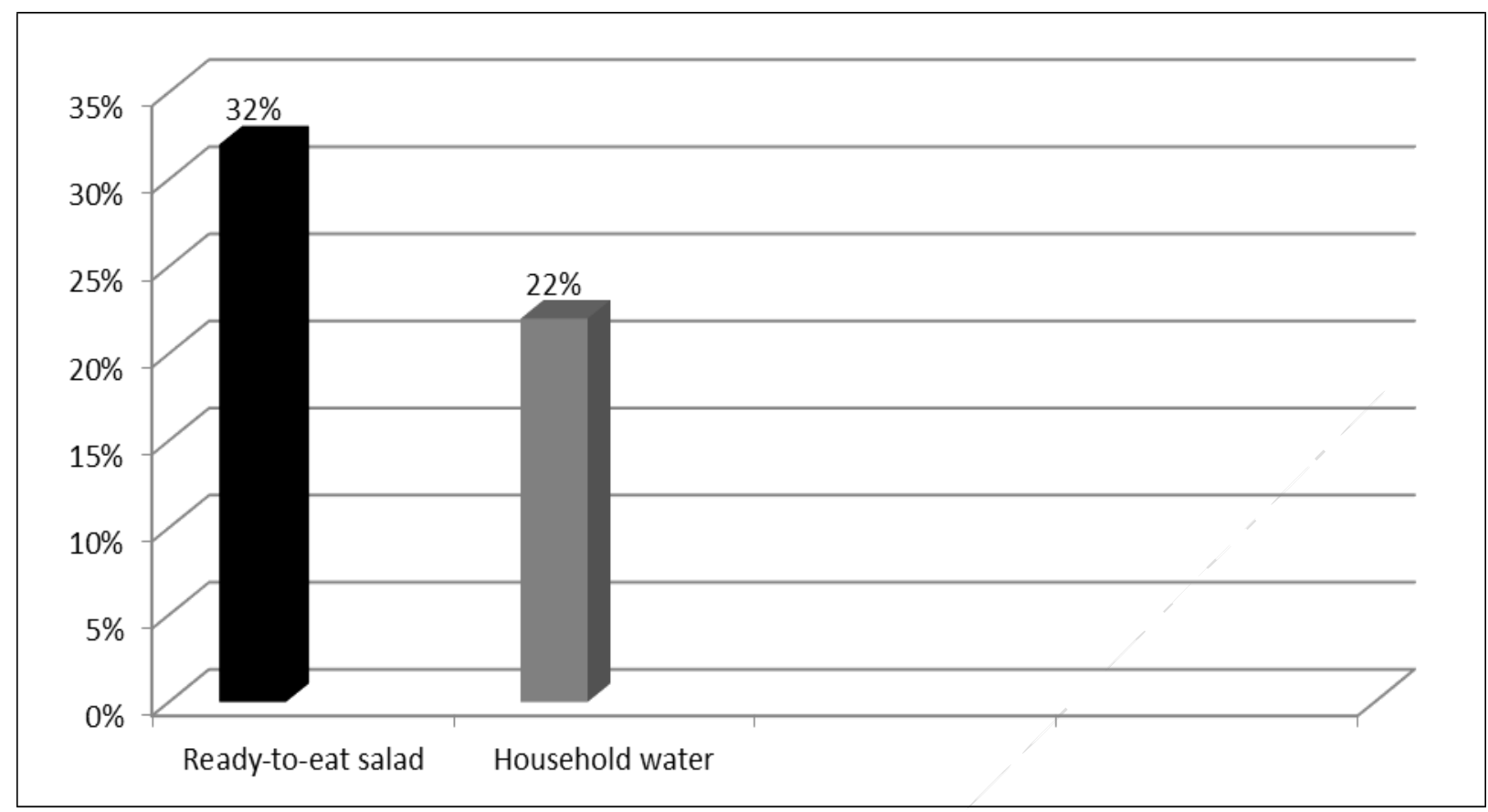

Figure 1.Prevalence of Shigella in ready-to-eat salad and household water

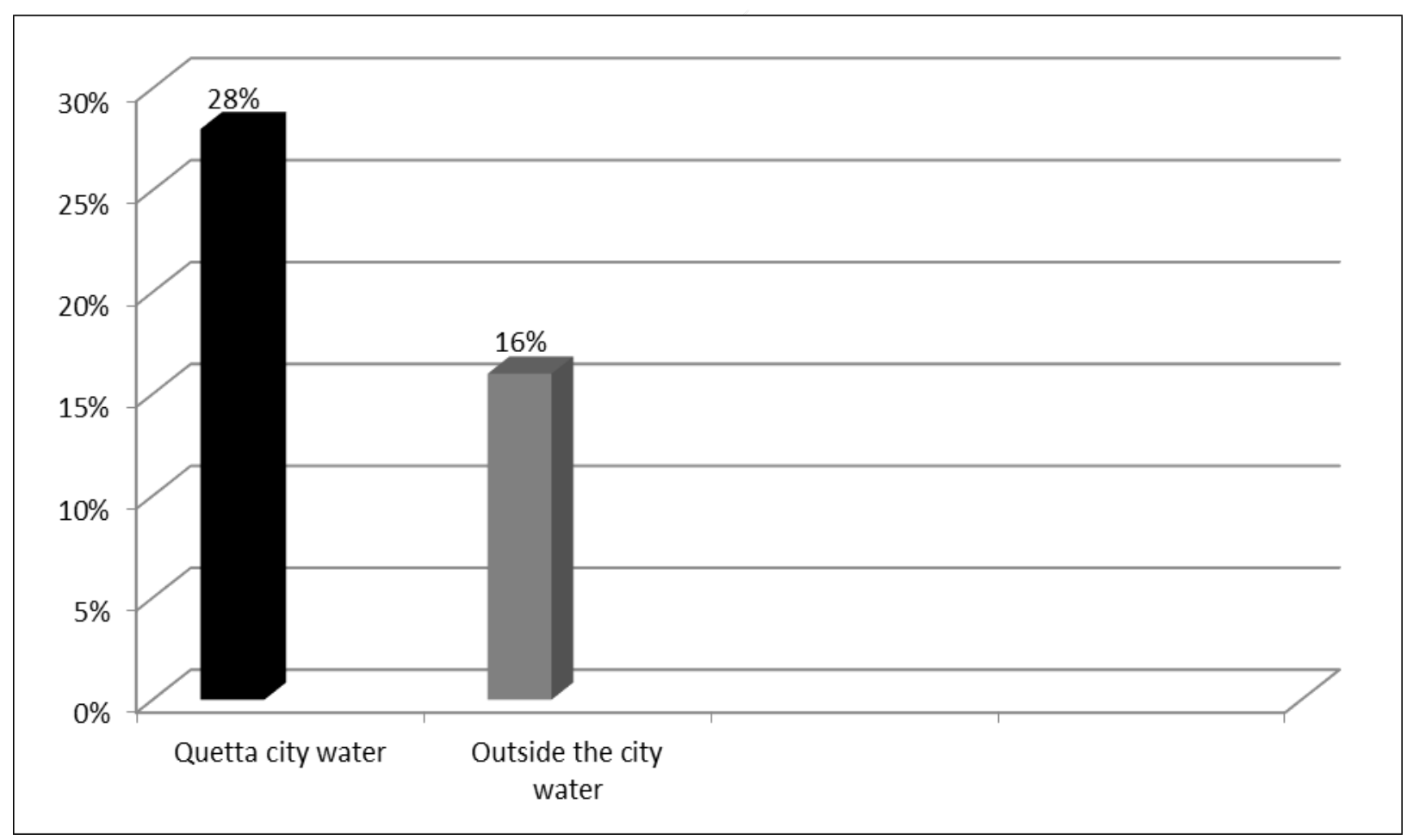

Figure 2. Prevalence of Shigella in Quetta city water and outside the city water 
Table 1. Result of Biochemical tests for Identification of S. flexneri and S. dysenteriae.

\begin{tabular}{|c|c|c|}
\hline Biochemical Tests & Shigella flexneri & Shigella dysenteriae \\
\hline $\mathrm{H}_{2} \mathrm{~S}$ from TSI & 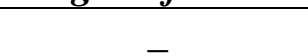 & 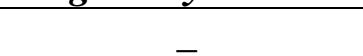 \\
\hline Gas from glucose (TSI) & - & _ \\
\hline Motility & - & - \\
\hline Urease & _ & _ \\
\hline L-Lysine decarboxylase & - & _ \\
\hline L-Ornithine decarboxylase & - & - \\
\hline Indole formation & + & + \\
\hline Sodium acetate & _ & - \\
\hline Christensen's citrate & - & - \\
\hline Dulcitol & + & + \\
\hline Glucose & + & + \\
\hline Lactose & - & - \\
\hline Mannitol & + & - \\
\hline Raffinose & + & - \\
\hline Salicin & - & _ \\
\hline Sorbitol & + & + \\
\hline Sucrose & _ & - \\
\hline Xylose & _ & + \\
\hline
\end{tabular}

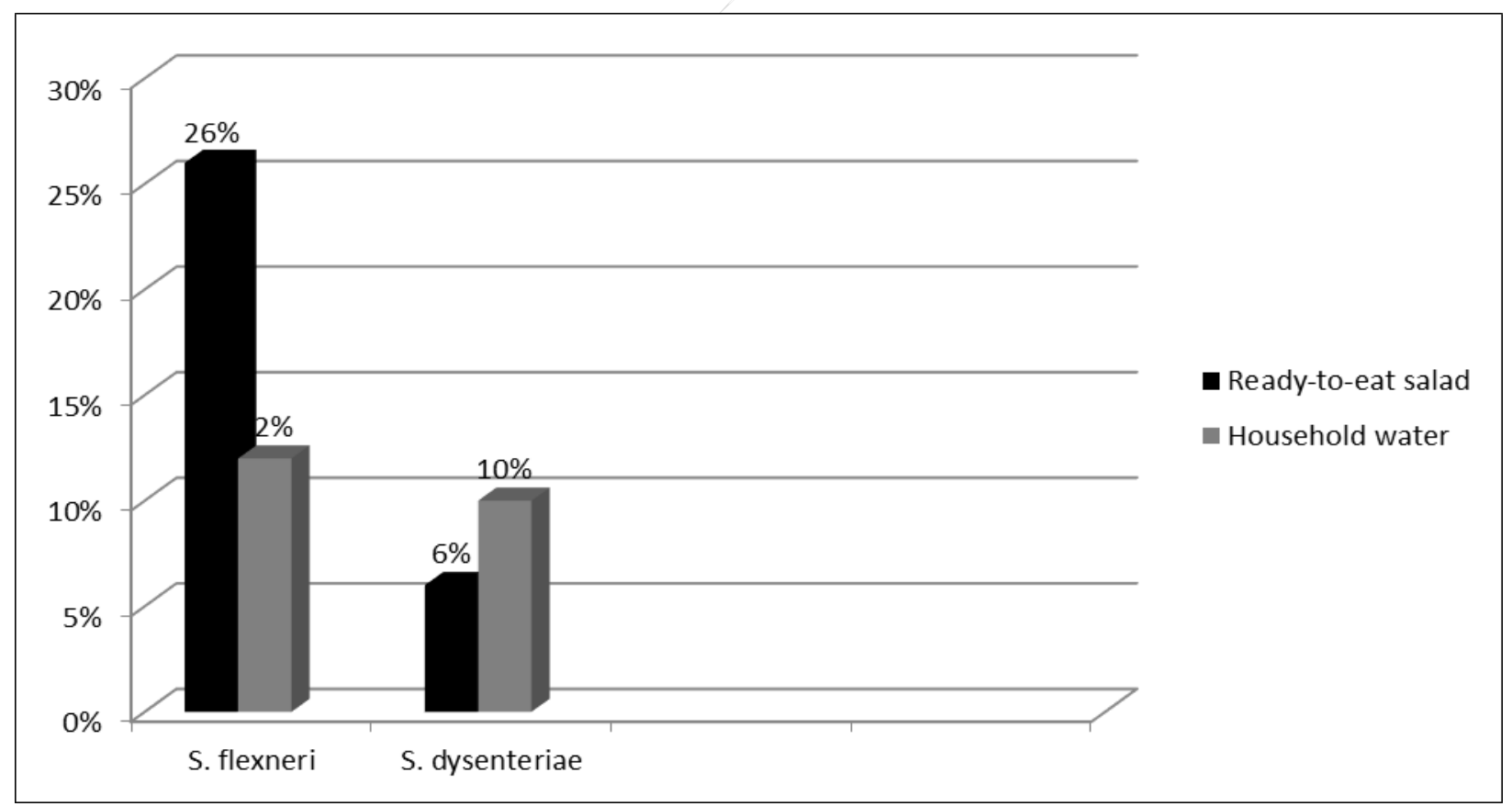

Figure 3. Percentage of Shigella flexneri and Shigella dysenteriae in the ready-to-eat vegetables and water samples 


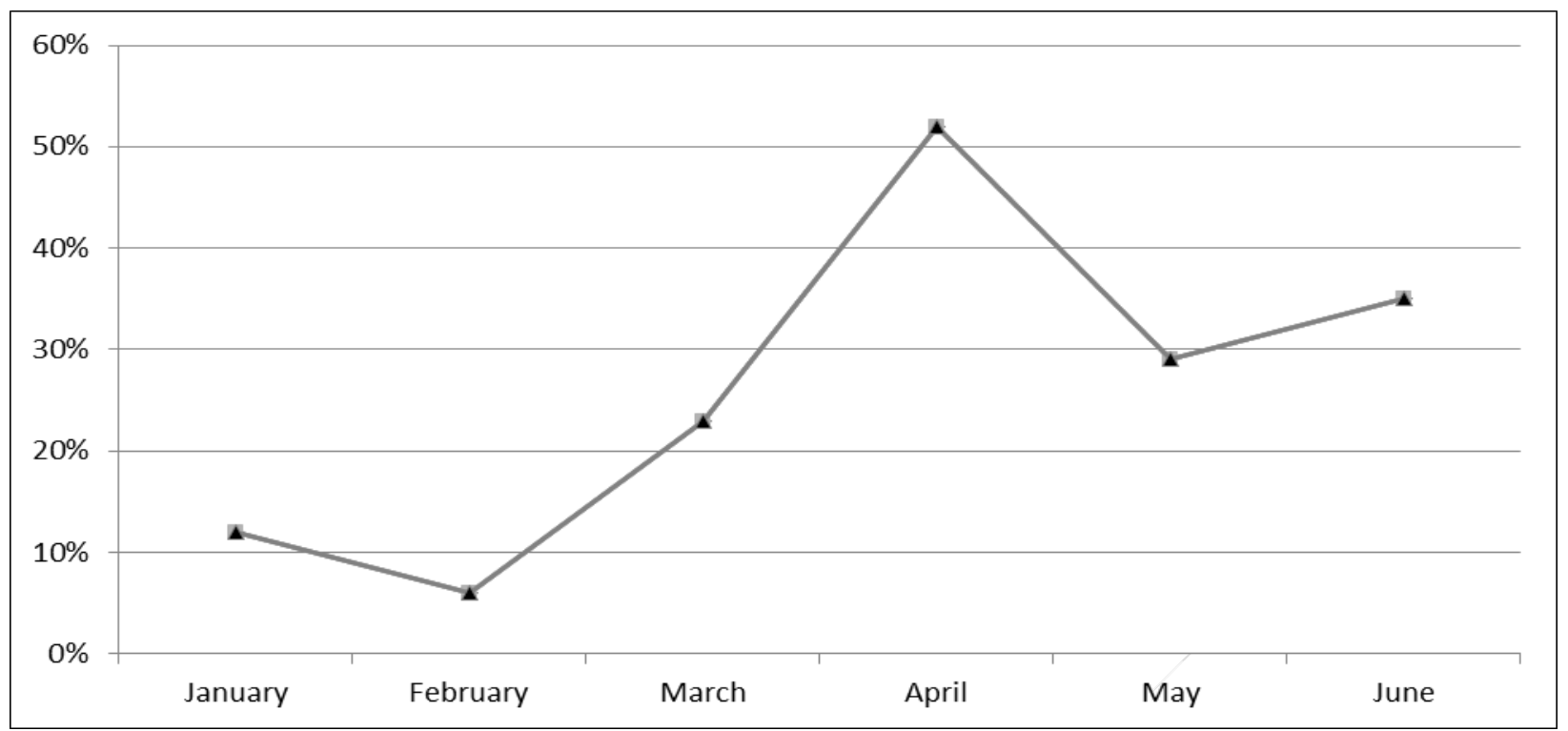

Figure 4. Month wise prevalence rate of Shigella

\section{Discussion}

Shigellosis is primarily a food and waterborne disease in developing and developed countries. The frequency of Shigella species and prevalence of shigellosis varies in different regions of the world. In the present study a total of 100 samples (50 ready-to-eat salad +50 household water) were analyzed during a period of January to June 2017, out of 100 samples Shigella species were isolated and biochemically characterized from 27 samples. Out of these 27 positive samples, 16 $(32 \%)$ were from ready-to-eat salad samples

According to the study conducted in India by Joy et al. [19], $66.6 \%$ of the ready-to-eat salads were contaminated with Shigella species, which is higher than the current study. In Nigeria (5.6\%) Shigella was isolated from ready-to-eat vegetables by Onyemeluk and Njokuobi, [20] which is lower than the present study. These findings were in contrast with the study reported by Soriano et al. [21] in Spain, where Shigella was not detected in any of the ready-to-eat salad served in Spain University restaurants. Several researchers have concluded that several outbreaks of shigellosis were and $11(22 \%)$ were from water. The results of the present study correlate with the findings of Biniam et al. [17] in Ethiopia, who isolated (37\%) of Shigella species from ready-to-eat salad. Study carried out by Mokhtari et al. [18] reported Shigella mostly from raw vegetables in Nabeul and Tunisia. There was a high prevalence rate of Shigella species within the samples of ready-to-eat salad. This shows the use of unsafe water for washing and sprinkling the vegetable to keep them fresh.

associated with the consumption of fresh products that are prepared by hand and are served uncooked or raw [22-24]. In addition, previous research data indicated that consumption of unhygienic food is the most common contributing factor in shigellosis in underdeveloped and developed nations [2527]. The detection of Shigella species from ready-to-eat salad revealed the inadequate safety and quality of these products.

In current study the percentage of Shigella species isolated from the household water was $(16 \%)$. The results of present study are consistent with study reported by Rasel et al. 
[28] in Bangladesh, who isolated Shigella species from surface water. A study by Ahmed et al. [29] observed $71.0 \%$ prevalence of Shigella species in Rawalpindi, Islamabad region in Pakistan, from drinking water sample of different dams and related filtration plant, which is higher than the prevalence in household water of current study. A study conducted in Yaounde, Yongsi et al. [30] identified 1242 isolates of Enterobacteriaceae family from a variety of drinking water, of which Shigella species had $0.24 \%$ incidence, which is lower than the present study. The finding of this study confirm the prevalence of Shigella species in household water and indicates, that it is due to poor sanitation, mixing of sewage water with fresh water and due to the contamination of fresh water with fecal material.

In this study two species of Shigella were isolated, Shigella flexneri and Shigella dysenteriae. Shigella flexneri was the most frequent species in the current study. Similar findings were noted in a study carried out in India by Dhodapkar et al. [31]. According to previous studies conducted in Egypt, Iran, India [32-34] and a multicenter study by Seliden et al. [35] done in Bangladesh, Pakistan, China, Indonesia and Viet Nam Shigella flexneri was found as the most frequent species. In contrast, a study conducted in Iran and Thailand where Shigella sonnei was the most frequently isolated serotype $[35,36]$.

The results of our study about month wise distribution showed that the prevalence rate of Shigella was higher in April, followed by June and May. Similar findings were reported by Hossain et al. [37] who observed high prevalence in April and May in Bangladesh. Various research studies claim that the seasonal tendency of shigellosis is summer $[32,38,39]$. In April, the temperature rises and summer season starts so the cases of shigellosis occurred more than the other months. The high prevalence in summer indicates that temperature and $\mathrm{pH}$ of water are also responsible for the prevalence of Shigella during the summer season.

\section{Conclusion}

The study concluded that the use of raw animal manure as fertilizer, irrigation of vegetable with fecal contaminated water, a poor sanitary system and improper treatment of water supplies can increase the threat of contamination of ready-to-eat salad and water. To control shigellosis good hygiene, safe handling and processing of food, using clean cutting boards for vegetable, adequate cooking of food, properly washing of raw vegetables before serving, use of boiled water and protection of food from flies are recommended. Awareness regarding communicable diseases also helps control shigellosis and other diarrheal disease.

\section{Authors' contributions}

Conceived and designed the experiments: A Samad, F Abbas \& Saima, Performed the experiments: Saima, Analyzed the data: M Rizwan, M Naeem, O Pokryshko \& S Diaconescu, Contributed materials/ analysis/ tools: M Yousaf, S Saifullah, Y Hassan \& M Zahid, Wrote the paper: Saima \& Roomeela.

\section{References}

1. Izumiya $\mathrm{H}$, Tada $\mathrm{Y}$, Ito $\mathrm{K}$, Morita-Ishihara T, Ohnishi M \& Terajima J (2009). Characterization of Shigella sonnei isolates from travel-associated cases in Japan. J Med Microbiol 58: 1486-1491.

2. Bardhan P, Faruque ASG, Naheed A \& Sack DA (2010). Decreasing shigellosis-related deaths without Shigella species specific interventions, Asia. Emerg Infect Dis 16: 1718-1723.

3. Wen X, Wu Y, Bian F, Sun Y \& Zheng X (2012). High prevalence of atypical class- 1 integrons and class- 2 integrons in multidrug resistance Shigella flexneri isolated from China. Afr J Microbiol Res 6: 69876993.

4. Heiman KE \& Bowen A (2013). Shigellosis. In: Travelers' Health (Ed.). Infectious Diseases Related to Travel. Centers for 
Disease Control and Prevention, 1600 Clifton Rd. Atlanta, GA, USA. 30: 333.

5. Scallan E, Hoekstra RM, Angulo FJ, Tauxe RV \& Widdowson MA et al. (2011). Foodborne illness acquired in the United States-major pathogens. Emerg Infect Dis 17: 7-15.

6. Painter JE, Walker AT, Pytell J, Nua MT \& Soliai-Lemusu S et al. (2015). Notes from the field: outbreak of diarrheal illness caused by Shigella flexneri American Samoa, May-June 2014. MMWR Morb Mortal Wkly Rep64:30.

7. Anon (2005). Shigellosis: disease burden, epidemiology and case management. Wkly Epidemiolo Record 80(11): 94-9.

8. Yabuuchi E (2002). Bacillus dysentericus (sic) 1897 was the first taxonomic rather than Bacillus dysenteriae 1898. Int $J$ SystEvolMicrobiol52: 1041.

9. Ud-Din A \& Wahid S (2014). Relationship among Shigella species and enteroinvasive Escherichia coli and their differentiation. Braz J Microbiol, 45: 1131-1138.

10. Von Seidlein L, Deok RK, Mohammad A, Hyejon L, Xuan, Yi W, Vu Dinh T, Do Gia C et al. (2006). A Multicentric study of shigella diarrhea in six Asian countries: Disease burden, clinical manifestation and microbiology. PLoS Med 3(9): 353.

11. Livio S, Strockbine NA, Panchalingam S, Tennant SM, Barry EM \& Marohn ME (2014). Shigella isolates from the global enteric multicenter study inform Vaccine development. Clin Infect Dis 933-941.

12. Phalipon A \& Sansonetti PJ (2007). Shigella's ways of manipulating the host intestinal innate and adaptive immune system: a tool box for survival. Immun Cell Biology 85(2): 119-29.

13. Marteyn B, Gazi A \& Sansonetti P (2012). Shigella: a model of virulence regulation in vivo. Gut Microbes 3(2): 104-120.

14. Patil DP \& Lava R (2012). Identification, characterization and antibiotic susceptibility of Shigella species isolated from stool samples in children. Int $J$ Biological Med Res 3(2): 1640-1643.
15. World Health Organization. (2006). Initiative for vaccine research (IVR). New vaccines against infectious diseases: research and development status. World Health Organization, Geneva, Switzerland.

16. International Organization for Standardization (ISO 21567:2004 (F)) (2004). Microbiology of foods and animal feeding stuffs- Horizontal method for the detection of Shigella species. Premtere edition 01-11-2004.

17. Biniam Guchi \& Mogessie Ashenafi (2010). Microbial load, prevalence and antibiograms of Salmonella and Shigella in lettuce and green peppers. Ethiop $J$ Health Sci 20(1): 41-48.

18. Mokhtari W, Nsaibia S, Majouri D, Ben Hassen A, Gharbi A \& Aouni M (2012). Detection and characterization of Shigella species isolated from food and human stool samples in Nabeul, Tunisia, by molecular methods and culture techniques. J Appl Microbiol 113(1): 209-22

19. Lewis Joy Joy E, Thomson Patrina, Rao BVVBN, Kalavati C \& Rajanna B (2004). Human bacteria in street vended fruit juices: A case study of Visakhapatnam city. India Int J Food Safety 8: 35-38.

20. Onyemeluk NF \& Njoku-Obi AN (1992). Shigellosis in Eastern Nigeria: Etiological frequency of serotypes and resistance to antibiotics. Lett Appl Microbiol 14:266270.

21. Soriano JM, Rico H, Molto JC \& Manes J (2000). Assessment of the microbiological quality and wash treatments of lettuce served in University restaurants. Int $J$ Food Microbiol 58(123): 123-12.

22. Mead PS, Slutsker L, Dietz V, MaCaig LF, Bresee JS, Shapiro C, Grippin PM \& Tauxe RV (1999). Food-related illness and death in the United States. Emerg Infect Dis 5: 1-21.

23. Wu FM, Doyle MP, Beuchat LR, Wells JG, Mintz ED \& Swaminathan B (2000). Fate of Shigellasonnie on parsley and methods of disinfection. J food Port 63: 568-572. 
24. Kuo HW, Kasper S, Jelovcan S, Hoger G, Lederer I, Koing C, Prinding G \& Luckner-Hornischer A (2009). A foodborne outbreak of Shigellasonnie gastroenteritis, Austria, 2008. Wien Klin Wochenschr 121: 157-163.

25. Mensah P, Yeboah-Manu D, OwusuDarko K \& Ablordey A (2002). Street foods in Accra, Ghana: how safe are they? Bull World Health Organ 80: 546-554.

26. Warren BR, Parish ML \& Schneider KR (2006). Shigella as a food-borne pathogen and current methods for detection in food. Crit Rev Food SciNutr 46: 551-567.

27. Lewis HC, Kirk M, Ethelberg S, Stafford R, Olsen KE \& Nielsen EM (2007). Outbreaks of shigellosis in Denmark and Australia associated with imported baby corn, August 2007- final summary. Euro Surveill 12: 3279.

28. Rasel K, Faruque SM Kamruzzaman M,Shinji Yamasaki, Shafi Ahmad Q,Tasnim Azim, Balakrish Nair G, Yoshifumi Takeda, David A \& Sack (2002). Isolation of Shigella dysenteriae Type 1 and S. flexneri Strains from Surface Waters in Bangladesh: Comparative Molecular Analysis of Environmental Shigella Isolates versus Clinical Strains. Appl Environ Microbiol 68(8): 3908-3913.

29. Ahmed T, Kanwal R, Tahir SS \& Naseem $R$ (2004). Bacteriological analysis of water collected from different dams of Rawalpindi, Islamabad region in Pakistan. Pak J BiolSci 7(5): 662-666.

30. Nguendo-Yongsi HB (2004). Microbiological Evaluation of Drinking Water in a Sub-Saharan Urban community (Yaounde). Ameri $J$ BiochemMolBiol 1: 68-81.

31. Dhodapkar R, Acharya NS, Harish BN \& Parija SC (2008). Shigellosis in Puducherry. Indian J Med Res127: 621-2.
32. Abu-Elyazeed RR, Wierzba TF, Frenck RW, Putnam SD, Rao MR, Savarino SJ, et al. (2004). Epidemiology of Shigellaassociated diarrhea in rural Egyptian children. Ameri J Trop Med Hyg 71: 36772.

33. Mamatha B, Pusapati BR \& Rituparna C (2007). Changing patterns of antimicrobial susceptibility of Shigella serotypes isolated from children with acute diarrhea in Manipal, South India, 5-year study. Southeast Asian J Trop Med Public Health 38: 863-6.

34. Urvashi Saxena S \& Dutta R (2011). Antimicrobial resistance pattern of Shigella species over five years at a tertiary-care teaching hospital in north India. J Health PopulNutr 29: 292-5.

35. von Seidlein L, Kim DR, Ali M, Lee H, Wang X, Thiem VD, et al. (2006). A multicentre study of Shigella diarrhoea in six Asian countries: disease burden, clinical manifestations, and microbiology. PLoS Med 3: 353.

36. Farshad S, Sheikhi R, Japoni A, Basiri E \& Alborzi A (2006). Characterization of Shigella strains in Iran by plasmid profile analysis and PCR amplification of ipa genes. J Clin Microbiol 44: 2879-2883.

37. Hossin MD, Albert MJ \& Hasan KHZ (1990). Epidemiology of shigellosis in Teknaf, a coastal area of Bangladesh: a 10year survey. Epidemiol Infect 105: 41-49.

38. Alici O, Acikgoz ZC \& Gamberzade S (2006). Antibiotic resistance rates of Shigella species isolated from stool cultures in the years 1999-2003. Microbial Bul 40(1-2): 9-14.

39. Savadkoohi RB \& Kacho MA (2007). Prevalence of Shigella species and their Antimicrobial Resistance Patterns at Amir kolachildren'shospital, North Iran. Iran J Pediatr 17(2): 118-22. 